\title{
Cotidiano e anonimato nas cidades: a enunciação peregrina de Rubem Fonseca
}

\author{
Vera Lucia Follain de Figueiredo*
}

\begin{abstract}
Resumo
Partindo de depoimentos de autores de narrativas de ficção cujas obras ganharam notoriedade na década de 90 do século passado, este artigo consiste numa reflexão sobre a especificidade da literatura urbana de Rubem Fonseca, considerando a estreita relação entre a mobilidade dos pontos de vista e o deslocamento cotidiano dos personagens nas grandes cidades.

Palavras-chave: Literatura. Cotidiano. Cidade. Realismo. Ponto de vista da narrativa.
\end{abstract}

Das ruas transversais, da Assembleia, do Ouvidor, do Rosário, começaram a surgir pessoas, homens, mulheres, famílias inteiras, carregando cobertores, sacas, esteiras, jornais velhos. As esteiras e os jornais velhos eram colocados no chão, sob as marquises das lojas, e eles se acomodavam, grudados uns nos outros como pencas de bananas. Recolhiam-se cedo, para dormir, pois acordavam antes do sol raiar. Preferiam as portas dos bancos, os banqueiros têm a consciência pesada e relutam em tentar expulsá-los.

(FONSECA, 1995, p. 131)

Rubem Fonseca tem sido frequentemente apontado como o escritor que inaugura a literatura urbana no Brasil. No entanto, sua obra retoma toda uma tradição de autores brasileiros que fizeram, da cidade, cenário de suas histórias, como Joaquim Manoel de Macedo, Machado de Assis, João do Rio, dentre outros. Além disso, é importante lembrar que seu primeiro livro, Os prisioneiros, foi publicado em 1963, ano de estreia também de João Antônio, com Malagueta, perus e bacanaço, livro que descortinava para o leitor a São Paulo dos malandros, dos pequenos crimes, dos trabalhadores humildes. A publicação de Feliz ano novo, em 1975, coincide com a de Leão-de-chácara, de João Antônio, e a de A faca no coração, de Dalton Trevisan. Considerando-se que, além dos mencionados,

* Pontifícia Universidade Católica do Rio de Janeiro (PUC Rio). Professora Associada do Departamento de Comunicação Social da PUC Rio. Pesquisadora CNPq. 
outros escritores surgidos nos anos de 1960 e 1970 também contribuíram para consolidar, entre nós, uma ficção que tem a cidade como palco dos dramas vividos pelos personagens, caberia perguntar o que, na verdade, há no texto de Rubem Fonseca que lhe confere esse destaque quando se fala de uma mudança de eixo na literatura brasileira. A linguagem coloquial, a concisão, o corte sincrônico do enredo, que marcam sua obra, são características que, desde o modernismo, como se sabe, estão cada vez mais presentes na literatura brasileira, sendo partilhadas, por exemplo, com os textos de Dalton Trevisan. Perguntamos, então, o que levaria, o escritor Cristóvão Tezza a afirmar:

O primeiro nome a se consolidar entre nós talvez de forma completa com o perfil de escritor urbano, no que essa definição tem de mais desenraizado (a ausência de um sotaque regional, a cidade como espaço abstrato de relações não familiares e transformadoras, cosmopolita ou tendendo rapidamente ao cosmopolitismo; o universalismo como um valor desejável), foi Rubem Fonseca. [...] sua obra estratifica parte substancial da imagem de um mundo urbano brasileiro e num certo sentido dá uma nova direção a uma parte da nossa literatura mais nova. (TEZZA, 2012, p. 188).

Existe uma diferença, sutil que seja, entre ambientar histórias na cidade e fazer literatura urbana? É o que sugere Luiz Ruffato quando afirma que, "até o surgimento da ficção de Rubem Fonseca, a literatura urbana esteve ligada ao mundo rural, sendo que mesmo nos autores mais urbanos, não havia ainda uma mentalidade urbana" (RUFFATO, 2003, p.2). Ou ainda Fernando Bonassi quando declara: Rubem Fonseca foi o primeiro escritor a escrever sobre a cidade "sem achar que ela é uma destruição do homem ingênuo do interior que vem para cá” (BONASSI, 2003). Para ele, Rubem Fonseca inaugurou uma visão sem preconceito da cidade:

Histórias de caras que saem para atropelar os outros, histórias de putas, histórias de médicos e funcionários públicos. Tudo isso sem demonizar a cidade, sem dizer que a cidade é a razão da infelicidade daquelas pessoas. Ele é primeiro que trabalha essa temática sistematicamente. (BONASSI, 2003)

Mas como se pode caracterizar, na obra de Fonseca (2011), isto que se está chamando de mentalidade urbana? José, ficção memorialística, publicada em livro em 2011, nos oferece algumas pistas para tentarmos responder a essa pergunta. 
Para além da declaração do personagem-narrador segundo a qual "a maior de todas as criações do ser humano é a cidade" (FONSECA, 2011, p. 47), as memórias de José estão inseparavelmente entrelaçadas com a história do Rio de Janeiro. O narrador fala de si sem se colocar no centro do discurso: no centro do discurso de José não está a reconstituição do seu passado, está o Rio de Janeiro - cidade para a qual se muda, "vindo diretamente de Paris", pois, embora até os oito anos morasse com os pais numa confortável casa em Juiz de Fora, não vivia de fato, segundo declara, na cidade mineira, mas na capital francesa dos livros de Michel Zevaco, Ponson du Terrail e Alexandre Dumas. Entretanto, se Paris era habitada e percorrida pelo ato de ler, o Rio será lido pelo ato de caminhar. Perambular pela cidade é o sucedâneo rival da leitura - do traçado das letras, e do traçado das ruas emergem as histórias que fascinam José:

Mas agora a leitura encontrara uma rival, a cidade, e José parava de ler a fim de perambular pelas ruas do Centro, quando conseguia escapar da vigilância da mãe. E as imagens, sons e cheiros daquela cidade chamada São Sebastião do Rio de Janeiro o despertaram para uma outra realidade e o fizeram descobrir um novo e atraente mundo, deram-lhe uma nova vida. (FONSECA, 2011, p. 35).

Literatura e cidade estão, desse modo, intrinsecamente ligadas, assim como ler e caminhar. ${ }^{1}$ Ao contrário do que se podia esperar, José não tem nenhuma tristeza pela perda da casa da família, nenhuma nostalgia em relação ao período da infância passado na tranquilidade da cidade mineira. Aliás, o José das memórias é apenas mais um dentre os vários Josés que povoam a cidade e a literatura do autor. Josés cuja existência não se define a partir de uma genealogia, mas se constitui na cidade e pela cidade.

Desde o título do livro, percebemos a opção por atenuar a marca biográfica, apostando, ao contrário, na indiferenciação: isto é, o nome duplo do autor José Rubem - usado no círculo que lhe é mais próximo, remetendo para uma identidade privada, é cindido, elegendo-se o primeiro, o mais comum, para designar o sujeito das memórias, e o segundo, acompanhado do sobrenome, para designar aquele que assina a obra. Antes mesmo de abrir o livro, temos de lidar com este desdobramento em três identidades que se tangenciam, mas não se sobrepõem - José Rubem, José e Rubem Fonseca - o que, de antemão, abala 
qualquer confiança num eu autoral único, garantia de verdade ou de ancoragem na realidade. A identidade homonímica entre autor, narrador e personagem é evocada para ser dissolvida nas fraturas do nome próprio. Assinale-se, ainda, que numa obra em que a narrativa em primeira pessoa é dominante, justamente o livro de memórias de José é narrado em terceira pessoa.

Os diversos Josés na obra de Rubem Fonseca têm poucos traços distintivos, vivendo à revelia no anonimato cotidiano das grandes aglomerações urbanas, e é a partir dessa adesão pedestre ao cotidiano da cidade que se constitui a enunciação peregrina, que caracteriza a ficção do autor. A mobilidade do olhar, no esforço de leitura do tecido social para captar o que as ruas escondem e revelam, traz à cena, por exemplo, no livro Amálgama, tanto o anônimo apaixonado do conto "Amor", que anda pelas ruas sem querer voltar para casa, porque ninguém o espera, como o narrador de "Matador de corretores", que declara:

As pessoas andam pela cidade e nada veem. Veem os mendigos? Não. Veem os buracos nas calçadas? Não. As pessoas leem livros? Não, veem novelas de televisão. Resumindo: as pessoas são todas umas cretinas. [...] Mas eu, quando ando pelas ruas, vejo tudo. E vejo a pior coisa de todas: a cidade sendo destruída. (FONSECA, 2013, p. 80).

Contrapondo-se à indiferença que caracteriza o homem apressado que circula nas grandes metrópoles, o José do conto mencionado, que pode ter qualquer outro nome ou não ter nome, não importa, resolve fazer alguma coisa em defesa da cidade, isto é, matar vendedores de imóveis. Como outras figuras criadas por Rubem Fonseca, acompanha a repercussão de suas ações pelos jornais - estes são frequentemente referidos pelos personagens do autor, que se valem da própria invisibilidade para agir, mas, contraditoriamente, contam com a imprensa para conferir notoriedade aos seus atos: expectativa já presente no protagonista de "O cobrador", que dá título ao livro publicado em 1979: "Leio os jornais. A morte do muambeiro da Cruzada nem foi noticiada. O bacana do Mercedes com roupa de tenista morreu no Miguel Couto e os jornais dizem que foi assaltado pelo bandido Boca Larga. Só rindo.” (FONSECA, 1979, p. 165).

Espelhos infiéis do cotidiano urbano, os jornais, regidos pelo sensacionalismo, famintos de grandes acontecimentos, desinteressados das "insignificâncias" do cotidiano, acabam por incitar a violência ostentatória: 
Uma pequena notícia? Que absurdo, eu queria causar um choque emocional e sai aquela merreca de notícia? Então tive outra ideia brilhante. A notícia saiu na primeira página. Corretor de imóveis é assassinado. Sua cabeça e os seus dedos foram decepados. O assassino deixou um bilhete vou assassinar um corretor por dia. (FONSECA, 2013, p. 81).

Também em Amálgama, o personagem de “O ciclista”, que circula de bicicleta pela cidade, entregando mercadorias, reporta-se à violência que escapa aos nossos olhos quando nos deslocamos distraídos pelas ruas - aquela violência da qual os jornais não falam:

Andando de bicicleta pela cidade a gente tem uma boa ideia do mundo. As pessoas são infelizes, as ruas são esburacadas e fedem, todo mundo anda apressado, os ônibus estão sempre cheios de gente feia e triste. Mas o pior não é isso. O pior são as pessoas más, aquelas que batem em crianças, que batem em mulheres, urinam nos cantos das ruas. (FONSECA, 2013, p. 60).

Heróis ou anti-heróis anônimos, de ética duvidosa, estes Josés são homens quaisquer, cuja identidade está sempre ameaçada pela dispersão cotidiana que "recusa os valores heroicos, porque recusa ainda mais todos os valores e a própria ideia de valor, arruinando sempre novamente a diferença abusiva entre autenticidade e inautenticidade", como destacou Blanchot (2007, p. 245). Sem referenciais fixos de identidade e valor, os Josés podem ser dedicados cuidadores de idosos, mas também podem ser assassinos profissionais ou executivos, loucos, detetives ou escritores. Sempre sujeitos às contingências, aos encontros fortuitos e passageiros, que a cidade, filha e mãe do deslocamento, lhes proporciona, partilham aquela proximidade, ou melhor, aquela promiscuidade feita de distanciamentos, muito própria da vida urbana, à qual se refere, por exemplo, um conto como "Buraco na Parede", cujas tensões decorrem da convivência forçada pela contiguidade dos espaços habitados pelos personagens. No sobrado velho, onde o narrador alugava um cubículo, a privacidade era artigo de luxo, as vidas eram inevitavelmente entrelaçadas. Despejado, é na rodoviária - lugar de passagem por excelência - que busca abrigo. Avaliando suas perdas, ele indaga:

Agora estou aqui, no banco da rodoviária, cercado de outros viajantes estremunhados segurando malas e embrulhos, novamente olhando as pessoas passarem e pensando na vida. Se eu não tivesse 
ido morar no sobrado de dona Ariana a minha vida seria outra? Mas fui morar lá porque quis e não saí de lá na hora certa porque não quis. (FONSECA, 1995, p. 139).

Mesmo ao buscarem refúgio na natureza, os personagens do autor se deparam com o fenômeno crescente de urbanização do mundo, que se realiza não só pelos movimentos de migração do campo para a cidade, mas também pelos processos urbanizadores que ultrapassam o território das cidades, através dos meios de comunicação, da internet, da velocidade dos meios de transporte, fazendo com que todos os espaços sejam, de uma forma ou de outra, percebidos por uma mentalidade urbana. Em "Viajem de Núpcias", por exemplo, um casal rico e educado resolve fazer turismo selvagem na lua de mel. Considerando que, como dizia o professor de filosofia da jovem esposa, "as cidades do mundo são concêntricas, isomórficas, sincrônicas" e que "só uma existe e você está sempre na mesma" (FONSECA, 1997, p. 42), os recém-casados escolhem descer as corredeiras do "remoto, selvagem e poderoso" rio Colorado, que atravessa "a dramática e fascinante" rocha de 300 metros de altura - tal como anunciado no folheto turístico. $\mathrm{O}$ folheto, entretanto, indo contra todo o espírito de aventura, também informa que: "toda balsa tem um toalete especial, que é diariamente esvaziado num depósito antisséptico da balsa e depois levado para a sede da empresa de turismo", sendo "proibido urinar ou fazer qualquer coisa no terreno" já que "o solo e cada pedaço de pedra são preservados e protegidos por lei" (FONSECA, 1997, p. 42). O casal do conto, cheio de códigos de cerimônia, de ascetismos burgueses, vivendo num apartamento clean, uma vida clean, busca algo que fuja ao já conhecido e à rotina vivida na cidade planetarizada. Entretanto, a própria maneira como planeja a viagem de núpcias chama a atenção para a apropriação, pelo imaginário urbano, da representação das forças selvagens e dionisíacas da natureza, colocada a serviço da venda de produtos diversos, dentre eles, os lazeres programados, vendidos pelo turismo.

A mobilidade dos pontos de vista, a pluralidade das vozes na literatura de Rubem Fonseca está, desse modo, em consonância com o espaço da cidade, que não só é atravessado por vias de circulação, mas está por inteiro em circulação, em circuitos, em idas e voltas, em transportes. Movimento que a obra do autor absorve com suas remissões de um texto a outro, no jogo das citações e paródias. Literatura e cidade afinam-se, assim, no modo de circulação do sentido. Em ambas, temos um modo de circulação infinito do sentido, que se opõe ao estabelecimento de verdades últimas. Como observou Jean-Luc Nancy: 
Quando se está em um modo finito de sentido, isto é, em um modo segundo o qual o sentido finaliza em uma remissão geral a uma realidade primeira ou última anterior a todos os signos - se poderia dizer remissão final dos signos a uma assinatura ou a uma significação, na qual a remissão se acaba, se aplaca, se imobiliza então se está em um mundo da religião. (NANCY, 2013, p. 113).

Para o filósofo francês, a cidade "não é, por casualidade, contemporânea do fim, se não da religião, ao menos do mundo religioso, do fim de uma ordem organizada por sua relação com os deuses" (NANCY, 2013, p. 114). Seria a suspensão desta relação num contexto mundano, temporal ou secular que teria feito emergir a cidade em plena configuração. As palavras de Jean-Luc Nancy nos remetem para o mundo sem Deus dos personagens de Rubem Fonseca, onde não há pecado nem culpa, não há mais que um incessante Mal sem consciência: "se o Mal é uma ocupação, um trabalho, uma distração, uma chama que arde por arder no deserto da vida cotidiana, qual é, então, a transcendência do Mal?"- pergunta o escritor argentino Tomás Eloy Martínez (2009), refletindo sobre a ficção do autor brasileiro. Assim, se Deus morreu, José, o narrador do romance O Seminarista, não vê maiores problemas em abraçar a carreira de assassino de aluguel, mantendo, no entanto, o hábito de citar brocardos latinos, que, de alguma forma, lhe servem de referência. Da formação religiosa recebida, restam pequenos fragmentos de textos, transformados em máximas e veiculados numa língua também morta, que, ironicamente, os legitima. O que nos faz lembrar também a resposta do narrador de Vastas Emoções, pensamentos imperfeitos ao lhe perguntarem qual era o seu sonho de consumo:

Acreditar em Deus, eu disse.

Isto mudaria alguma coisa?

Talvez o meu estilo. Minha linguagem é assindética, cheia de elipses de conjunção. A fé tornaria meu estilo hiperbólico, polissindético. Etc. Na época pensei que estava brincando. (FONSECA, 1988, p. 67).

O sentido errante une a cidade e a literatura. A figura do passante e do leitor se sobrepõem em suas perambulações pelas ruas ou pelas páginas dos livros. Perambulações que caracterizam, por exemplo, o personagem narrador da crônica "Exitus letalis" — incluída no livro O romance morreu (FONSECA, 2007) — que não percorre só obras reconhecidas como literárias, mas desliza por textos de 
diferentes espécies, lançando sobre eles um olhar inusitado, atento aos "sofisticados" recursos linguísticos e imagéticos que utilizariam. Leitor "onívoro ou polífago", como ele próprio se apresenta, suas leituras prediletas são de poesia e de bulas de remédio. Segundo o personagem "a bula, da mesma forma que a poesia, tem as suas metáforas, os seus eufemismos, os seus mistérios, e as partes melhores são sempre as que vêm sob os títulos "precauções" e/ou "advertências" e "reações adversas" (FONSECA, 2007, p. 39):

Trecho da bula de determinado remédio: "Uma proporção maior ou mesmo menor do que $10 \%$ de ..." (não cito o nome do remédio, aconselhado pelo meu advogado) "pode causar uma toxicidade que pode evoluir para exitus letalis" (o itálico é da bula).

Qual o poeta, mesmo entre os modernos, os herméticos ou os concretistas, capaz de eufemizar, camuflando de maneira tão rica, o risco da morte - "evoluir para exitus letalis"? (FONSECA, 2007, p. 39).

Talvez aí, na opção pelos deslizamentos dos pontos de vista, evitando a comodidade dos lugares fixos, encontremos o traço que mais distingue, o que se chamou de mentalidade urbana na ficção de Rubem Fonseca, bem como a dicção realista que a acompanha. A falta de fundamento, conforme observamos em obra anterior (2003), é responsável pelo registro artificioso do discurso de seus narradores, que deve ser levado em conta para que se evite o perigo de cair na armadilha da narrativa em primeira pessoa fonsequiana: esta borra os limites entre enunciado e enunciação, mas não para remeter para qualquer instância fora da ficção, como, por exemplo, o autor empiricamente considerado, e sim para o jogo infinito de simulações que afasta o espectro de um realismo ingênuo. $\mathrm{O}$ descentramento da perspectiva põe em xeque as certezas, inclusive as que fundamentam os discursos generosos e nobres de quem tem direito à palavra, como os artistas e os intelectuais. Nesse sentido, a literatura do escritor segue caminhos divergentes daqueles trilhados pela ficção realista de João Antônio que, "abraçado ao seu rancor", tendo como horizonte a defesa dos pobres e oprimidos, declara:

E, assim futricado, só escrevo porque tenho a consciência culposa. Um homem limpo vai para casa e dorme. Ou vive, ama. E não há fantasmas que o atormentem. Um homem de bem dorme (...). Desaprendi a pobreza dos pobres e dos merdunchos. E, já creio, aprendi a pobreza envergonhada da classe média (ANTÔNIO, 2001, p. 76). 
Diferentemente também dos discursos dos narradores exibicionistas do que se convencionou chamar de autoficção, através dos quais os escritores nada mais fazem do que girar em torno de si mesmos, a primeira pessoa da narrativa de Rubem Fonseca está a serviço da dispersão. Ou como disse o personagem Mandrake: "Minha cara é uma colagem de várias caras, isso começou aos dezoito anos; até então o meu rosto tinha unidade e simetria, eu era um só. Depois tornei-me muitos" (SCHNAIDERMAN, 1994, p. 538). Não se trata, desse modo, de afirmar ou negar a relação do texto com seu referente: trata-se de arruinar a utopia dos lugares próprios, as divisões. A narrativa em primeira pessoa fonsequiana não está a meio caminho entre a ficção e o real. Não mistura a experiência supostamente real do escritor e a história supostamente inventada do romance, como faz grande parte da literatura contemporânea: a obra do autor borra os limites entre enunciado e enunciação, mas para destacar o jogo infinito de simulações que constitui a construção das identidades, num mundo que só se configura na e pela linguagem.

Em cada livro de contos, a variação de pontos de vista, deixando o leitor sem o apoio de uma voz distanciada e moralizante, suscita a leitura dos fatos por ângulos diversos, abrindo caminho para que as verdades estabelecidas sejam colocadas sob suspeita. Em alguns contos de Histórias Curtas (FONSECA, 2015), por exemplo, para citar uma obra bem recente, a enunciação deslegitimada ao final da narrativa deixa o leitor sem chão, tão perplexo quanto o personagem narrador diante do aparato médico que desautoriza as suas palavras como puro delírio, pondo em dúvida a sua própria identidade. Quebra-se, desse modo, “o princípio de realidade da ficção", remetendo-se para a indiscernibilidade entre o discurso ficcional e o discurso dos loucos. A loucura, entretanto, também não tem um território bem delimitado, podendo ser identificada nos comportamentos que radicalizam valores disseminados pela sociedade. Assim o narrador de "A luta contra o preconceito racial" nos conta a estratégia que adotou ao levantar a bandeira do "politicamente correto", lutando contra os preconceitos: ter um filho com uma negra e outro com uma índia, o que lhe permitiria passear nas ruas com os bebês, portando o cartaz: "Tenho um filho de uma mulher negra e uma filha de uma mulher índia. Abaixo o preconceito racial." No final da história, deitado na cama do hospital, o narrador nos faz saber da decisão dos médicos de lhe aplicarem uma eletroconvulsoterapia.

O desenraizamento, apontado por Cristóvão Tezza, como marca da literatura urbana de Rubem Fonseca, atinge radicalmente, nunca é demais assinalar, a pretensa unidade de uma voz autoral: esta é minada pela pluralidade de eus e suas 
idas e vindas no mundo textual - que acaba abarcando tudo. Já em O caso Morel, a autoria se desdobrava nas figuras do criminoso e do escritor - e ambas remetiam para a figura do "autor empírico", que não precede o texto, não lhe é exterior, mas é fabricado por ele. Através do par Morel/Vilela, punha-se em fábula a posição fronteiriça atribuída ao escritor, que lhe permitiria ocupar diferentes lugares sem se fixar em nenhum deles, deslizar, em sua ficção, através das diferentes divisões sociais: "Gente como nós ou vira santo ou maluco, ou revolucionário ou bandido" (SCHNAIDERMAN, 1994, p. 461), diz o personagem de "Intestino Grosso", jogando com o imaginário social em torno da figura do escritor.

A relação entre autor, narrador e leitor é, assim, recorrentemente abordada, pontuando os contos e, principalmente, seus romances ensaísticos. Em Bufo \& Spallanzani, Rubem Fonseca (1985) recorre ao personagem-escritor para tematizar a literatura como eterna reescritura de obras alheias, como pura trajetória da letra à letra. O diário, gênero típico da escrita de si, da identificação entre aquele que vive e aquele que escreve, é visitado no romance Diário de um fescenino para que se desfaça exatamente esta identificação, num jogo de reflexividade infinita, através do qual retoma galhofeiramente a própria obra:

Esse meu novo livro não terá, como os outros que escrevi, personagens infelizes enredados em vicissitudes cotidianas. Será inflado com detalhes de um episódio importante da história universal, terá muitas páginas - os leitores gostam de romances grossos, nem que seja para colocar na estante - como o José e seus irmãos, do Thomas Mann (FONSECA, 2003, p. 44),

Seguindo esta linha, a fábula da "letra sem pai", do texto que, circulando no mundo separado da voz que o enuncia, pode ser atribuído a qualquer pessoa ou a um personagem-autor, será desenvolvida em várias narrativas de Rubem Fonseca nas quais o enigma a ser decifrado decorre da usurpação da autoria, da desconexão entre a assinatura que acompanha a obra e a identidade do autor empírico: narrativas cujas intrigas são tecidas a partir do descolamento entre origem e sentido. No conto "Artes e ofícios", o personagem tira partido da distância instituída pela escrita em relação ao corpo, assinando o romance da ghostwriter. Em "Romance Negro" (FONSECA, 1992), o enredo gira em torno da ficcionalização da figura do escritor, cuja imagem é construída pela mídia e vendida junto com a obra, através de reportagens, entrevistas e, mais recentemente, através da criação de blogs e da participação nas redes sociais da internet. A trama 
policial do conto se constrói a partir do enigma postulado pelo personagem-autor sobre sua própria identidade, colocando-se, portanto, em jogo a questão da autoria. O lugar do crime será o texto, porque, a partir dele, tudo se torna ficção, inclusive a biografia do escritor. Winner, o personagem-autor de romances policiais, inventa o seu próprio assassino - um escritor fracassado chamado Landers, que teria tomado lugar do verdadeiro Winner. Inventa um outro oculto, onde residiria a sua autêntica identidade, protegida dos holofotes. Defender a existência desse "outro" contra a descrença de todos é recuperar a dicotomia realidade/ficção que, quando dissolvida, provoca uma avalanche de demolições que levam ao silêncio. Por isso, "Romance Negro" termina com a pequena história do bobo que vivia dizendo que viu a sereia e, a partir do momento em que realmente ouve o seu canto, emudece: eliminando-se a distância entre realidade e ficção, não é mais possível o relato que desta se alimenta.

São frequentes, então, na obra do autor, os falsários que se apropriam de um nome ou de uma escritura, aproveitando-se da falha entre a voz e a letra, a partir da qual a própria literatura se constituiu. Essa falha, entretanto, deixa a literatura sempre sob a ameaça de se perder em meio aos discursos cotidianos, anônimos, flutuantes e passageiros que circulam na cidade, mas, uma vez suprimida, também promoveria o fim da literariedade, já que o próprio da literatura seria desmantelar as relações estáveis entre nomes, ideias e coisas. Por esse viés, um dos efeitos do atrelamento da ficção à vida do escritor, promovido pela cultura midiática de consumo, direta ou indiretamente, seria neutralizar a perturbação trazida pela escrita, conter as aventuras da letra sem corpo. É o propósito do mercado editorial de dar um corpo à letra dos romances, com o objetivo de aumentar as vendas, que gera a desgraça do personagem do conto intitulado "Best-Seller”, do livro Amálgama.

"Best-Seller” começa com a frase do editor: "Rua do pecado não vendeu nada". Em seguida, o autor retruca: "Eu li no jornal que era um dos mais vendidos". Ao que o editor responde: "Demos uma grana para sair aquela nota. Mesmo assim não adiantou" (FONSECA, 2013, p. 93). E acrescenta:

Você tem de escrever um romance autobiográfico, que conte a história de alguém da sua família com doença grave, uma doença que faça a pessoa sofrer muito, algo maligno que não seja mortal. Entendeu? É isso que os leitores querem hoje em dia, uma história que tenha veracidade. Ninguém quer mais ler ficção, a ficção acabou. É isso que vende. Você tem alguém assim na sua família? (FONSECA, 2013, p. 94). 
Com medo de decepcionar o editor, perdendo a oportunidade de publicação de um novo livro, o personagem escritor mente, dizendo que tinha uma história verídica para contar. De volta para casa, pensa em inventar o nascimento de um filho sem pernas e sem braços, fato que teria gerado o suicídio de sua mulher, ateando fogo às vestes, mas dessa ideia deriva a do escritor que está enlouquecendo, odeia todo mundo e resolve se matar ateando fogo às vestes. Resolve, então, em nome da autenticidade do que que irá descrever, ensaiar a cena do suicídio, e, sem querer, acaba tocando fogo nas próprias roupas, sofrendo queimaduras gravíssimas. No hospital, todo envolvido em ataduras, recebe a visita do editor que faz referência à grande divulgação do acidente no país e até no exterior: "Está no YouTube, no Facebook, em toda parte" (FONSECA, 2013, p. 98), diz ele, ao que o escritor responde, num enorme esforço para articular as palavras por entre as ataduras: "Foda-se". Antes de se retirar, entretanto, o editor lhe dá a melhor notícia de todas: "Rua do Pecado virou um best-seller. Já imprimimos duas vezes." (FONSECA, 2013, p. 98).

Neste conto, Rubem Fonseca transforma em matéria de ficção o processo de criação do escritor, a realidade da escrita e das condições de publicação, remetendo para a questão da exposição da vida privada do autor como estratégia de marketing, tão em voga nos dias de hoje: momento em que a narrativa de ficção parece mesmo estar em baixa, buscando legitimar-se com auxílio de procedimentos da esfera dos documentários, renunciando à mediação do trabalho formal, considerado como mero artifício. Ao ironizar o drama do escritor-celebridade, aprisionado na condição de personagem de si mesmo, Rubem Fonseca reafirma sua opção pelo regime de visibilidade instaurado pela literatura moderna, isto é, pela ficção que recorta as cenas urbanas, que desliza entre as ocupações cotidianas e os prazeres ordinários dos anônimos, deixando aflorar as vozes dos pequenos egos atormentados.

Dando continuidade, a seu modo, à poética do prosaico, que o romance europeu do século XIX consagrou - ao assumir, como destacou Jacques Rancière (2010, p. 67), a igualdade de todos os temas, rompendo a hierarquia entre sujeitos própria da ficção clássica - Rubem Fonseca dialoga com escritores como Balzac e Flaubert que, em sua época, também tentaram ler o mundo moderno como um amontoado de ruínas, onde se mesclam a vida cotidiana e a poesia. No entanto, se estes escritores buscavam decifrar o sentido oculto nas aparências, se, em seus textos, o banal torna-se belo como rastro do verdadeiro, como hieróglifo a ser 
decifrado, na literatura de Rubem Fonseca, hermenêutica e desatino caminham juntos. Não havendo nenhuma verdade oculta por trás da superfície, resta ao homem mover incessantemente as peças dispostas sobre ela, reordenando-as em busca de um sentido. A perda da crença numa dimensão profunda, em que a verdade se ocultaria, transforma tudo em imagens planas e intercambiáveis. Nos textos, como nos espaços urbanos, tudo é remissão de um lugar a outro, de uma escrita a outra, num incessante movimento de idas e vindas. Falta o fundamento que daria consistência ao real, conduzindo a um fechamento do sentido. A verdade, como as cidades, está sempre se deslocalizando, se descentralizando: é essa homologia que constitui a literatura urbana de Rubem Fonseca.

\title{
Daily lives and anonymity in cities: the pilgrim enunciation of Rubem Fonseca
}

\begin{abstract}
Relying on statements mentioned by authors of fictional narratives that gained notoriety in the $90 \mathrm{~s}$, this article elaborates on the specificity of the urban literature written by Rubem Fonseca, considering the close relationship between the alternate point of views and the dislocation of the characters in the big cities.
\end{abstract}

Keywords: Literature. Daily lives. City. Realism. Narrative point of view.

\section{Referências}

ANTÔNIO, João. Abraçado ao meu rancor. São Paulo: Cosac \& Naify, 2001. ANTÔNIO, João. Leão-de-chácara. São Paulo: Cosac e Naify, 2002.

ANTÔNIO, João. Malaguetas, perus e bacanaço. São Paulo: Cosacnaify, 2004. BLANCHOT, Maurice. Conversa infinita 2: a experiência limite. São Paulo: Escuta, 2007.

BONASSI, Fernando. "Entrevista concedida em 2003, a Claudinei Vieira e a Fransueldes de Abreu". Disponível em: http://www.igler.com.br. Acesso em: 20 março 2004.

FONSECA, Rubem. O caso Morel. Rio de Janeiro: Artenova, 1973.

FONSECA, Rubem. O cobrador. Rio de Janeiro. Nova Fronteira, 1979. 
FONSECA, Rubem. Bufo \&Spallanzani, Rio de Janeiro: Francisco Alves, 1985. FONSECA, Rubem. Vastas emoções, pensamentos imperfeitos. São Paulo: Companhia das Letras, 1988.

FONSECA, Rubem. Feliz ano novo. São Paulo: Companhia das Letras, 1989.

FONSECA, Rubem. Os prisioneiros. São Paulo: Companhia das Letras, 1991.

FONSECA, Rubem. Romance Negro e outras histórias. São Paulo: Companhia das Letras 1992.

FONSECA, Rubem. O buraco na parede. São Paulo: Companhia das Letras, 1995.

FONSECA, Rubem. Histórias de amor. São Paulo: Companhia das Letras, 1997. FONSECA, Rubem. Diário de um fescenino. São Paulo: Companhia das Letras, 2003.

FONSECA, Rubem. O romance morreu. São Paulo: Companhia das Letras, 2007.

FONSECA, Rubem. O Seminarista. Rio de Janeiro: Agir, 2009.

FONSECA, Rubem. José. Rio de Janeiro: Nova Fronteira, 2011.

FONSECA, Rubem. Amálgama. Rio de Janeiro: Nova Fronteira, 2013.

FONSECA, Rubem. Histórias curtas. Rio de Janeiro: Nova Fronteira, 2015.

GOMES, Renato. Todas as cidades, a cidade. Rio de Janeiro: Rocco, 2008.

MARTINEZ, Tomás Eloy. "Rubem Fonseca, o narrador do mal". Disponível em: terramagazine.terra.com.br. Acesso em: 01 abr. 2009.

NANCY, Jean-Luc. La ciudad a lo lejos. Buenos Aires: Manantial, 2013.

RANCIÈRE, Jacques. El espectador emancipado. Buenos Aires: Manantial, 2010.

RUFFATO, Luiz. Entrevista inédita concedida, na PUC-Rio, a Andréa Chauffaille Drummond. jun. 2003.

SCHNAIDERMAN, Boris (Org.). Contos reunidos/ Rubem Fonseca. São Paulo: Companhia das Letras, 1994.

TEZZA, Cristóvão. "Rubem Fonseca e sua prosa irresistível em dose dupla". In: FONSECA, Rubem. E do meio do mundo prostituto só amores guardei ao meu charuto. Rio de Janeiro: Nova Fronteira, 2012. 
TREVISAN, Dalton. Faca no coração. Rio de Janeiro: Record, 1979.

Recebido em 20/05/2016

Aceito em 06/09/2016 